\title{
Research of Microorganism Corrosion Properties of 2024-T31 Aluminum-Magnesium Alloy in Oil-Water System
}

\author{
Yan-yu Cui, Jia Li, and Qing-miao Ding \\ Airport College, Civil Aviation University of China, Tianjin 300300, China \\ Correspondence should be addressed to Yan-yu Cui; yycui@cauc.edu.cn
}

Received 20 January 2017; Revised 19 February 2017; Accepted 13 March 2017; Published 11 April 2017

Academic Editor: Flavio Deflorian

Copyright (C) 2017 Yan-yu Cui et al. This is an open access article distributed under the Creative Commons Attribution License, which permits unrestricted use, distribution, and reproduction in any medium, provided the original work is properly cited.

\begin{abstract}
The surface analysis techniques and chemical technical means (polarization curves and AC impedance technique) were applied to research the corrosion characteristics of microorganisms SRB of 2024-T31 aluminum-magnesium alloy in the oil-water system, and the corrosion mechanism was finally analyzed. The results showed that SRB accelerate the corrosion process and cause uneven pitting on the surface of the metal matrix. Passive and biological films control the corrosion of the metal substrate in bacterial oil-water system. In the initial stage of immersion, a loose and uneven biofilm formed on the surface of substrate which accelerated its corrosion. In the midterm, the effect of biofilm gradually weakened while the protective effect of the passive film grew more insistently; the rate of corrosion slowed down. In the later period, localized corrosion cell of large cathode/small anode formed on the surface of the substrate which accelerates the corrosion.
\end{abstract}

\section{Introduction}

With the rapid development of civil aviation industry in recent years, the reliability and safety of aircraft are of great importance to the life and property safety of the passengers on the plane. One of the critical factors that affects the reliability and safety of aircraft is the material, while the corrosion resistance of the material is particularly crucial. Complex environment like heat, salt spray, temperature changes, rain, and so forth may cause condensation at the aircraft structure cracks or low-lying $[1,2]$, which is similar to the accumulation of water in the tank. The aluminum-magnesium alloy and the high strength steel are breeding microorganisms and causing serious corrosion [3-5] for the main materials of the fuel tank.

The actual operate situations of aircraft are complex, such as heat, salt spray, mold, industrial pollution in the atmosphere, and the rain (or snow, fog, frost, dew, etc.), as well as the pollution of oil-water systems in the cabin; the corrosion will easily occur on the aircraft in such "complex environment," they are tremendous threats for the operation of the airplane. The fuel tanks which is mainly made of aluminum alloy and high strength steel are the structures most prone to corrosion [1]. Changes in the external environment, internal fuel, and the oil-water system separated from the natural oil during storage process may form the condensation at the gap of the aircraft structure $[1,2]$. The components of condensate are complex which contains many corrosive substances such as chloride ions and various heavy metals ions. Prolonged accumulation of them will breed microorganisms and cause severe corrosion [3-5].

2024-T31 aluminum-magnesium alloy has been widely used for the manufacture of aircraft fuel tanks, skin, skeleton, rib beams, wings, and other important components because of its great quality such as light weight, low density, high compression resistance, and excellent thermal conductivity. Once corrosion occurs because of the accumulation of water in the tank, the structure of aviation materials may have a serious threat for safety and even cause flight failures and disasters $[6,7]$.

At the current stage, there are few studies on the effects of microorganisms on the corrosion of oil tank water system. This thesis explores the corrosion characteristics of microorganisms SRB of 2024-T31 aluminum-magnesium alloy in the 


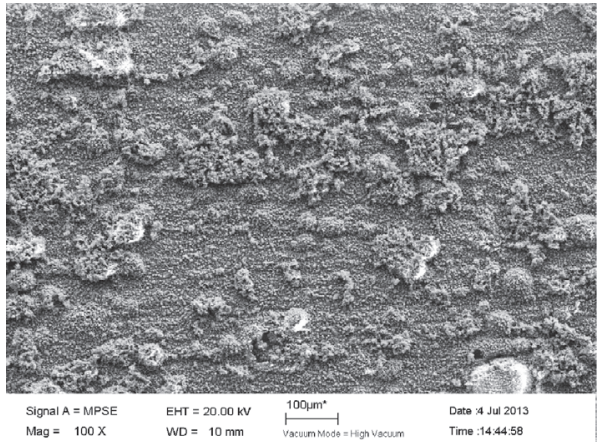

(a1)

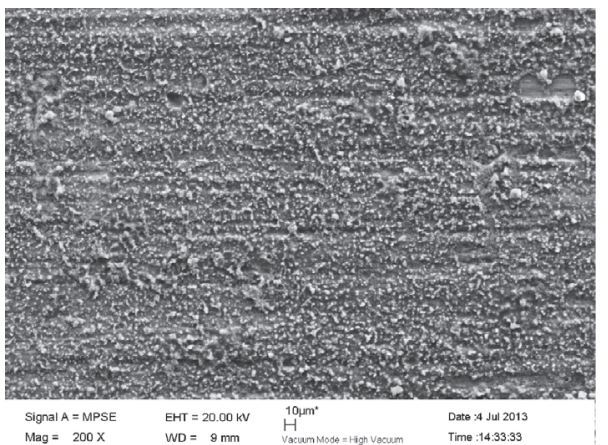

(b1)

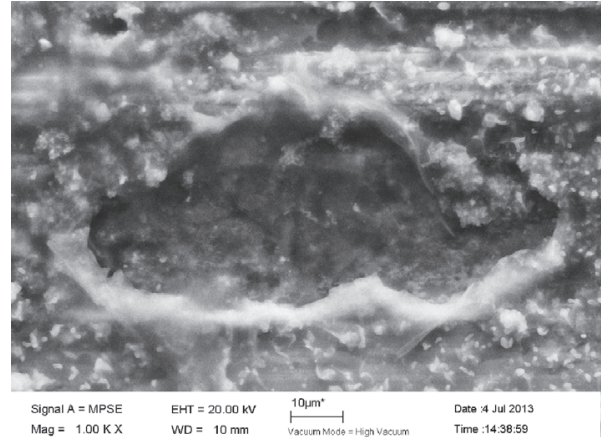

(a2)

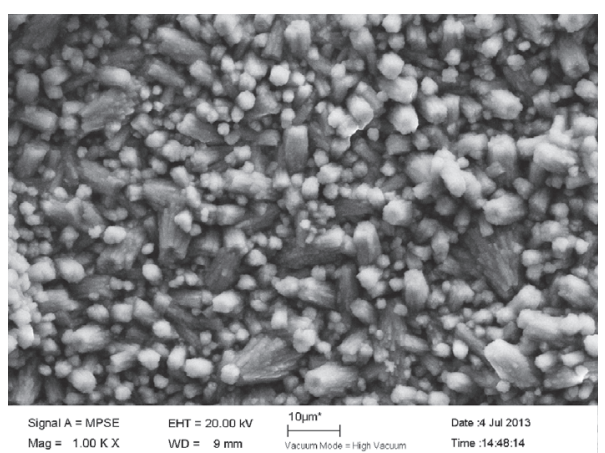

(b2)

FiguRE 1: Corrosion morphology of 2024-T31 aluminum-magnesium alloy soaked in different experimental systems for $30 \mathrm{~d}$ (1: low magnification observation; 2: high magnification observation).

TABLE 1: Chemical composition in 2024-T31 aluminum-magnesium alloy.

\begin{tabular}{lc}
\hline Chemical composition & Content (mass\%) \\
\hline $\mathrm{Cu}$ & $3.8-4.9$ \\
$\mathrm{Si}$ & 0.50 \\
$\mathrm{Fe}$ & 0.50 \\
$\mathrm{Mn}$ & $0.3-0.9$ \\
$\mathrm{Mg}$ & $1.2-1.8$ \\
$\mathrm{Zn}$ & 0.25 \\
$\mathrm{Cr}$ & 0.10 \\
$\mathrm{Ti}$ & 0.15 \\
$\mathrm{Al}$ & Margin \\
\hline
\end{tabular}

oil-water system, which may provide a theoretical basis for the effective use of aluminum-magnesium alloy.

\section{Experimental Methods}

2.1. Experimental Materials. 2024-T31 aluminum-magnesium alloy is selected as sample, the main chemical components of which are shown in Table 1 . We use metal sheet whose size is $40 \times 13 \times 12 \mathrm{~mm}$ and the surface area is $12 \mathrm{~cm}^{2}$. The electrochemical test sample is a cylinder with the diameter of $5 \mathrm{~mm}$ and the height of $10 \mathrm{~mm}$. The sample is spot welded with copper wire, sealed up with epoxy, and set aside by
$0.2 \mathrm{~cm}^{2}$. Before experiment, the sample was stepwise polished with 400\#-1000\# sandpaper, making sure the surfaces are polished. Oil and water are removed with acetone an absolute ethanol, respectively. Finally the sample was blown dry.

The sulfate reducing bacteria (SRB) are selected as experimental microbial strains which are extracted from the Institute of Oceanology. Forming oil-water hierarchy medium system, the medium system A consists of jet fuel and water and SRB bacteria; the medium system B consists of jet fuel and water.

2.2. Experimental Content. The 2024-T31 aluminum-magnesium alloy sample and the working electrode are immersed in different aqueous phases of test systems 1 and 2, sealed up, and put into the $30^{\circ} \mathrm{C}$ constant temperature biochemical incubator. Each of them has three parallel samples to conduct static hanging film test and electrochemical test with the culture period of $30 \mathrm{~d}$.

At the end of the static hanging test, the corrosion products are washed off in accordance with GB/T165451996, observing the corrosion morphology with LEO1530VP scanning electron microscope (SEM). Under the action of 100 to 30000 voltages, the electron beam transmitted by the gun is accelerated, going through the Electronic Optics System and forming a narrow electron beam focusing on the sample, scanning the sample with the scanning coil of the last lens, obtaining the image, and analyzing the corrosion products with EDS. 


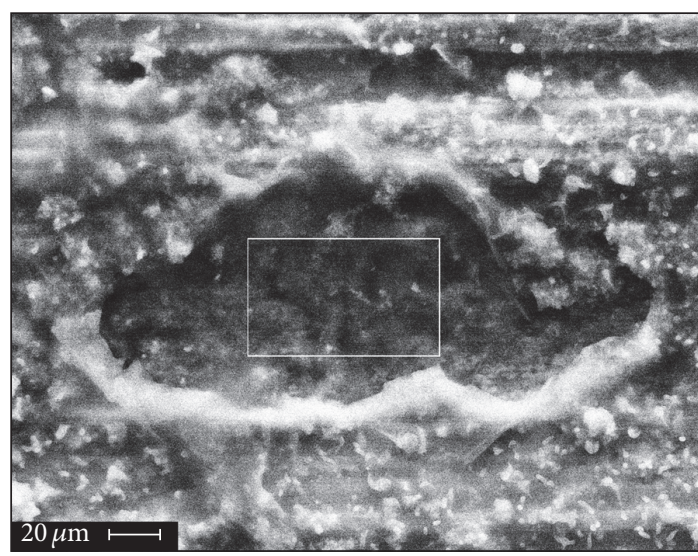

KV 20.0 MAG 1000 TILT 0.0 micronsperpixy 0.264 (a1)

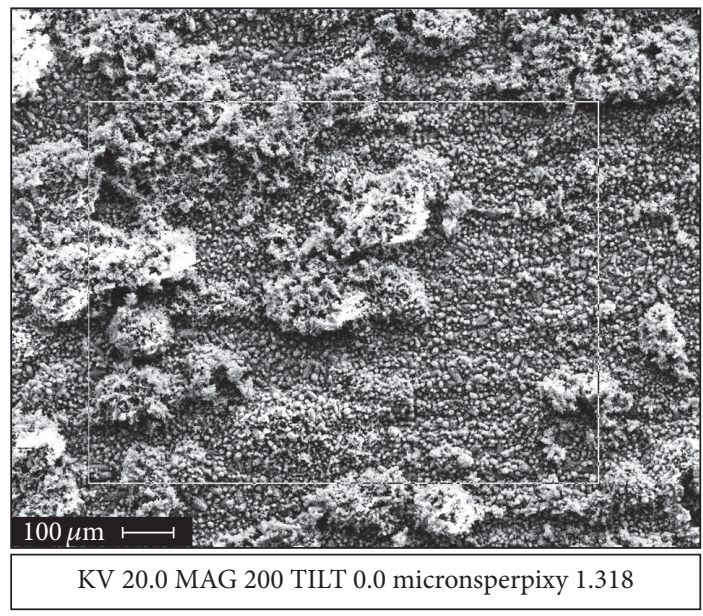

(b1)

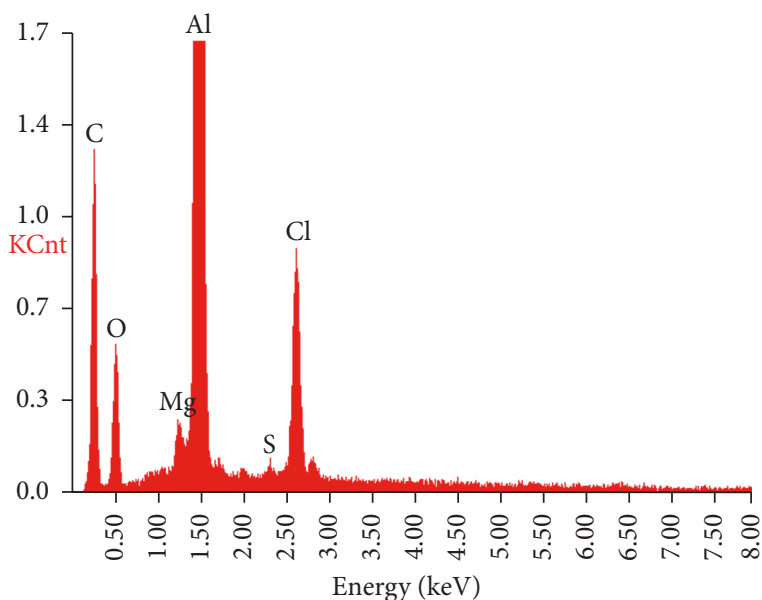

\begin{tabular}{lcc}
\hline Element & $\mathrm{Wt} \%$ & $\mathrm{At} \%$ \\
\hline $\mathrm{CK}$ & 52.40 & 69.09 \\
OK & 08.94 & 08.85 \\
MgK & 00.67 & 00.44 \\
AlK & 33.11 & 19.43 \\
SK & 00.24 & 00.12 \\
ClK & 04.64 & 02.07 \\
Matrix & Correction & ZAF \\
\hline
\end{tabular}

(a2)

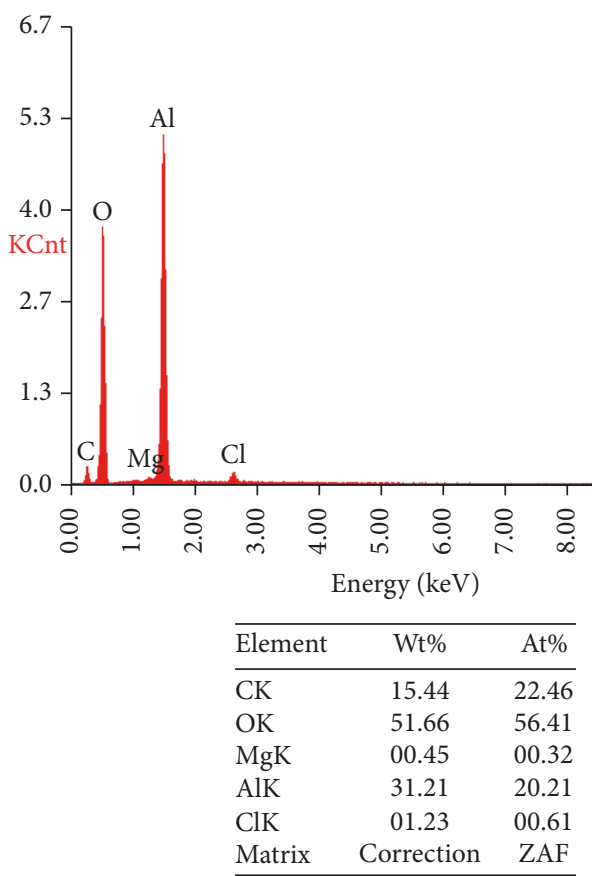

(b2)

FIGURE 2: Analyzing the corrosion product of 2024-T31 aluminum-magnesium alloy immersed in different experimental systems for $30 \mathrm{~d}$.

CHI660D electrochemical workstations are used to measure three electrode systems which are made of a platinum sheet auxiliary electrode with area of $1 \mathrm{~cm}^{2}$, a saturated calomel reference electrode (SCE), and the 2024-T31 aluminum-magnesium alloy working electrode. Electrochemical impedance test is measured by the self-corrosion potential with the frequency ranges of $0.01 \mathrm{~Hz}-10^{6} \mathrm{~Hz}$ and the amplitude of $5 \mathrm{mV}$, while in polarization curve test, the 

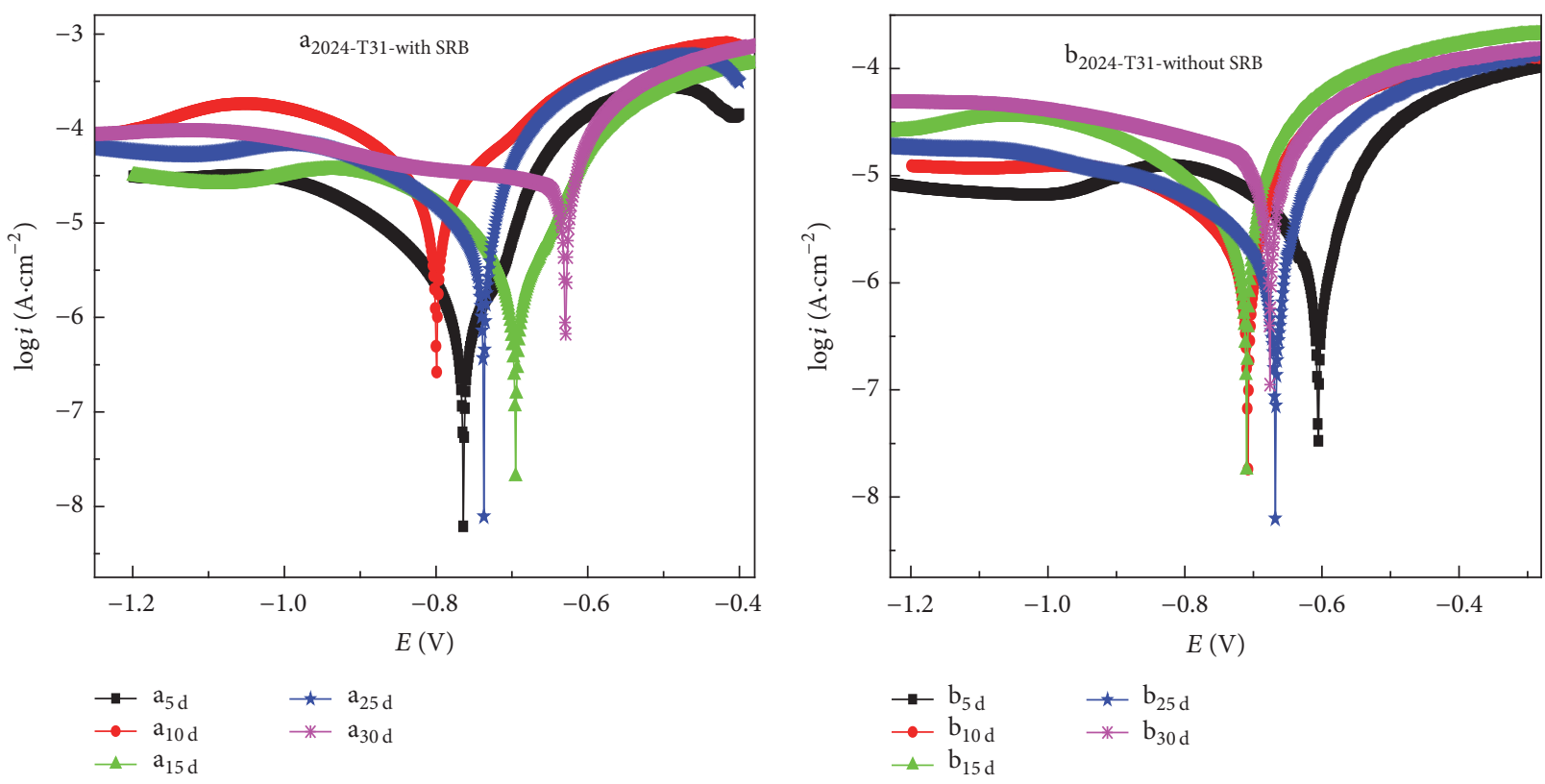

FIGURE 3: The polarization curves of 2024-T31 aluminum-magnesium alloy immersed in a and b experimental system for 5-30 d.

TABLE 2: Part parameters fitting magnetization curve of 2024-T31 aluminum magnesium alloy.

\begin{tabular}{lcccccccccc}
\hline Name & $\mathrm{a}_{5 \mathrm{~d}}$ & $\mathrm{a}_{10 \mathrm{~d}}$ & $\mathrm{a}_{15 \mathrm{~d}}$ & $\mathrm{a}_{25 \mathrm{~d}}$ & $\mathrm{a}_{30 \mathrm{~d}}$ & $\mathrm{~b}_{5 \mathrm{~d}}$ & $\mathrm{~b}_{10 \mathrm{~d}}$ & $\mathrm{~b}_{15 \mathrm{~d}}$ & $\mathrm{~b}_{25 \mathrm{~d}}$ & $\mathrm{~b}_{30 \mathrm{~d}}$ \\
\hline$\beta \mathrm{a}$ & 18.85 & 6.96 & 14.49 & 7.52 & 5.60 & 7.95 & 6.66 & 6.13 & 7.39 & 4.56 \\
$\beta \mathrm{c}$ & 4.89 & 4.45 & 5.20 & 4.41 & 1.97 & 6.94 & 5.33 & 5.71 & 5.44 & 2.855 \\
\hline
\end{tabular}

potential scan ranges are $-1.2 \mathrm{v}$ to $-0.4 \mathrm{v}$ and scanning speed is $0.1 \mathrm{mv} / \mathrm{s}$. Notice that all electrochemical measurements are performed at room temperature.

\section{Test Results and Discussion}

3.1. Corrosion Morphology. Figure 1 is the corrosion morphology of 2024-T31 aluminum-magnesium alloy which had been soaked in bacteria and sterile experimental system for $30 \mathrm{~d}$. As is shown in Figure 1, observing the alloy with low magnification microscope after $30 \mathrm{~d}$ in system A, there are nonuniform corrosion and metabolic products accumulating on the surface. Changing to high magnification microscope (a2), it has obvious pits which have deeper color at the middle area. Observing the alloy with low magnification microscope after $30 \mathrm{~d}$ in system $\mathrm{B}$, there is a relatively uniform and dense gray film on it and no significant corrosion occurred. Switching to high magnification microscope (b2), uniform columnar crystals gathered on the surface. With the extension of time, SRB metabolic activities, and the accumulation of its product, microorganism colonies are absorbed between alloy and medium solution, accelerating the corrosion of 2024-T31 aluminum-magnesium alloy substrate.

3.2. Corrosion Products EDX. Figure 2 is SEM and EDS spectra morphology of 2024-T31 aluminum-magnesium alloy which had been soaked in both bacteria and sterile experimental system for $30 \mathrm{~d}$. Figure 2 shows that we can detect
$\mathrm{C}, \mathrm{O}, \mathrm{Mg}, \mathrm{Al}, \mathrm{S}, \mathrm{Cl}$, and other elements in system $\mathrm{A}$ of the alloy while $S$ element was not found in corrosion products of system B. Known from the literature, SRB will produce acidic metabolites by metabolism, produce organic or inorganic sulfur compounds which deposited on the surface of the substrate, weaken the protective effect of the passive film, and accelerate corrosion procession of the substrate [8]. This indicates that the $\mathrm{S}$ element in corrosion products comes from corrosion reactions in which SRB are involved [9-12].

In conjunction with Figures 1 and 2 , the $\mathrm{Al}_{2} \mathrm{O}_{3}$ passivation film may be generated on the surface of system $B$. The aluminum will be passivized to form aluminum oxide once encountered with oxygen for it is a very reactive metal; this gray dense and strong film would completely isolate the inside metal from the outside world and protect the matrix from corrosion [13]. All of these are consistent with experimental results.

3.3. Polarization Curves of Different Systems. Figure 3 is the polarization curves of two 2024-T31 aluminum-magnesium alloy samples immersed in test systems A and B for different times. Table 2 shows the electrochemical parameters resulting from polarization curves.

It can be seen from Figure 3 and Table 2 that the magnitude of the moving polarization curve of 2024-T31 aluminummagnesium alloy in an experimental system is larger and the corrosion potential changes as follows in the soak cycle: negative shift-positive shift-negative shift; corrosion current 

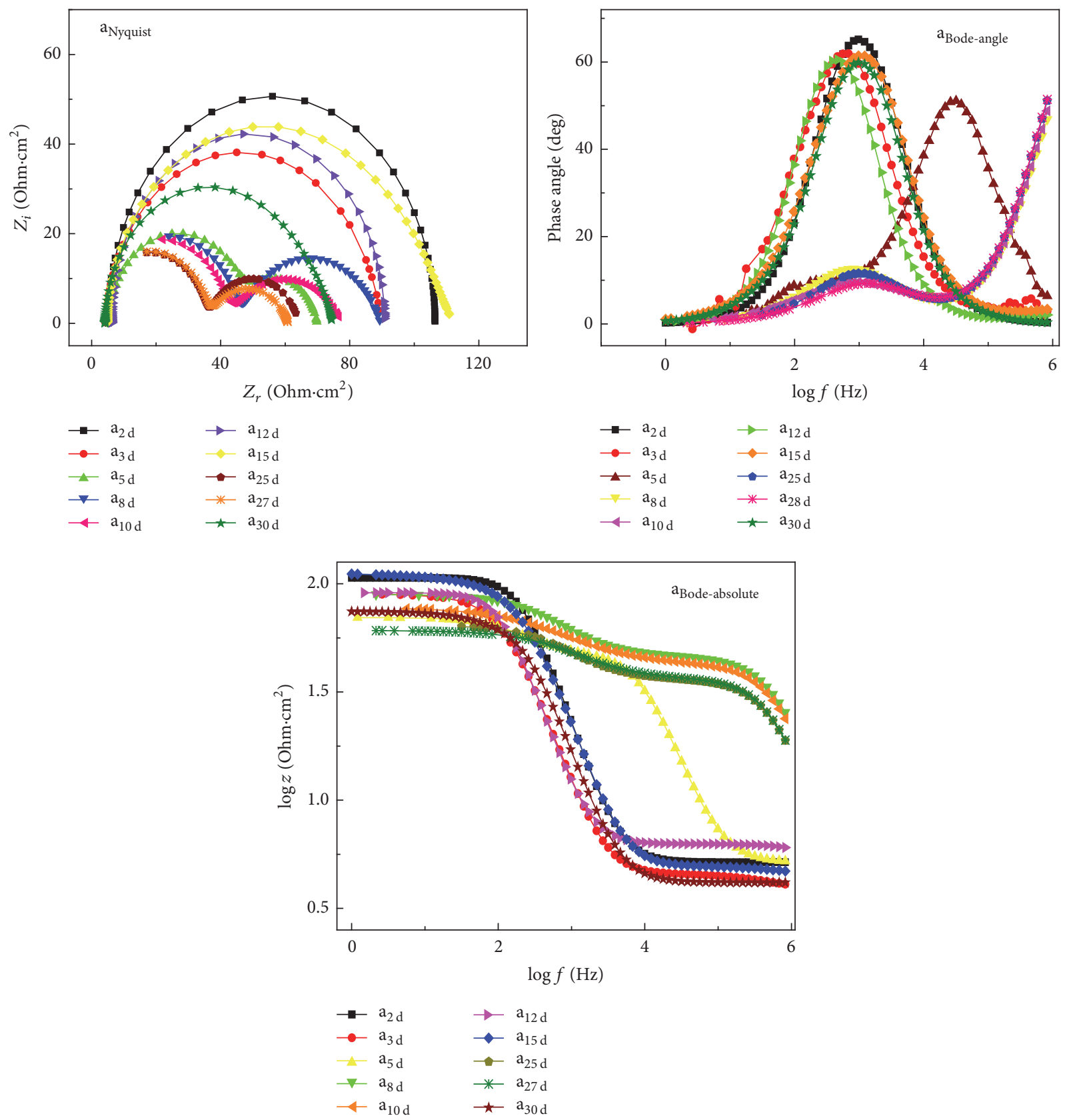

FIGURE 4: 2024-T31 aluminum-magnesium alloy was immersed in a test system 2-30 d of the Nyquist plot and Bode plot.

density changes as follows: increase-decrease-increase. The polarization corrosion potential in system B moves quickly to the negative direction in early immersion and then shifts towards positive direction slowly while the corrosion current density increases constantly. This is because aluminum is an active metal which can react with the free oxygen in media solution and form a layer of dense passive film on surface which can protect the substrate from corrosion [1315]. In the initial stage of the alloy in an experimental system, the SRB has high growth activity for its adequate nutrient resources. A large number of metabolites on the surface form an uneven biofilm which has positive influences on cathodic depolarization [16-19]. Moreover, SRB are a kind of anaerobic bacteria which lead to the decrease of the oxygen concentration on the substrate surface, inhibit the formation of passive film [20], accelerate the corrosion rate of the matrix alloy, and finally cause the negative shift of corrosion potential and the increase of corrosion current density; with the extension of time, the nutrients in system A are consumed gradually, and the extracellular polymers produced by the SRB adsorb on the oxidation passivation film which enhances the protective effect of the passive film, leading to the corrosion potential's positive shift and the decrease of current density. At the later stage of immersion, 

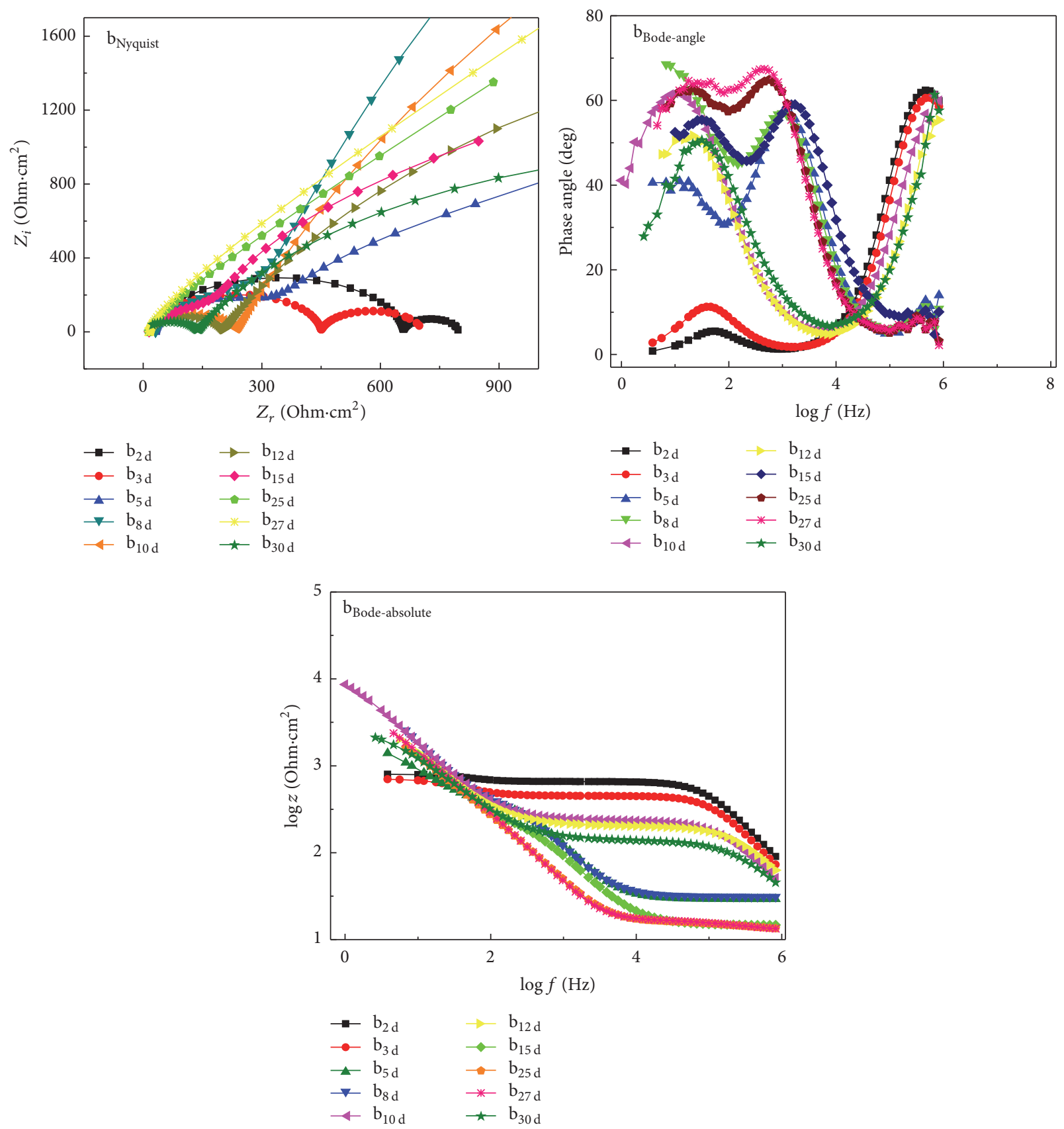

FIGURE 5: 2024-T31 aluminum-magnesium alloy immersed in b experimental system 2-30 d of the Nyquist plot and Bode plot.
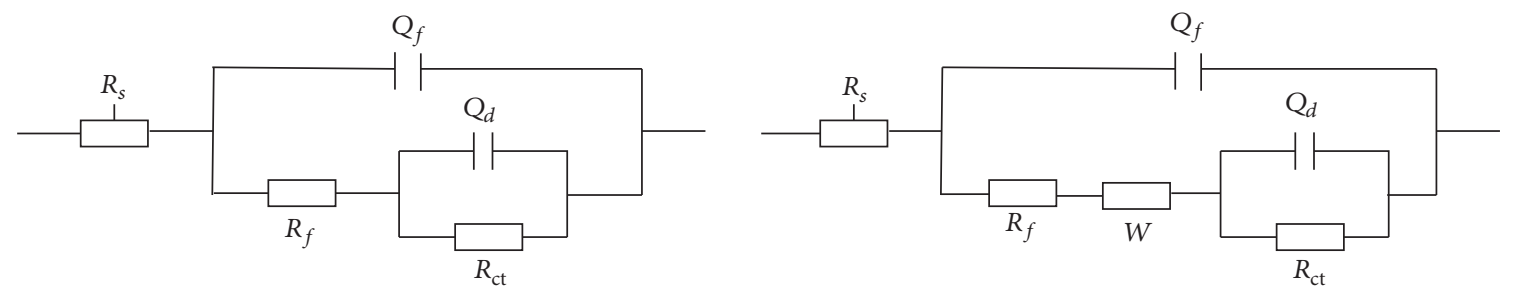

FIGURE 6: 2024-T31 aluminum-magnesium alloy in a and b equivalent circuit diagram of the experimental system. 


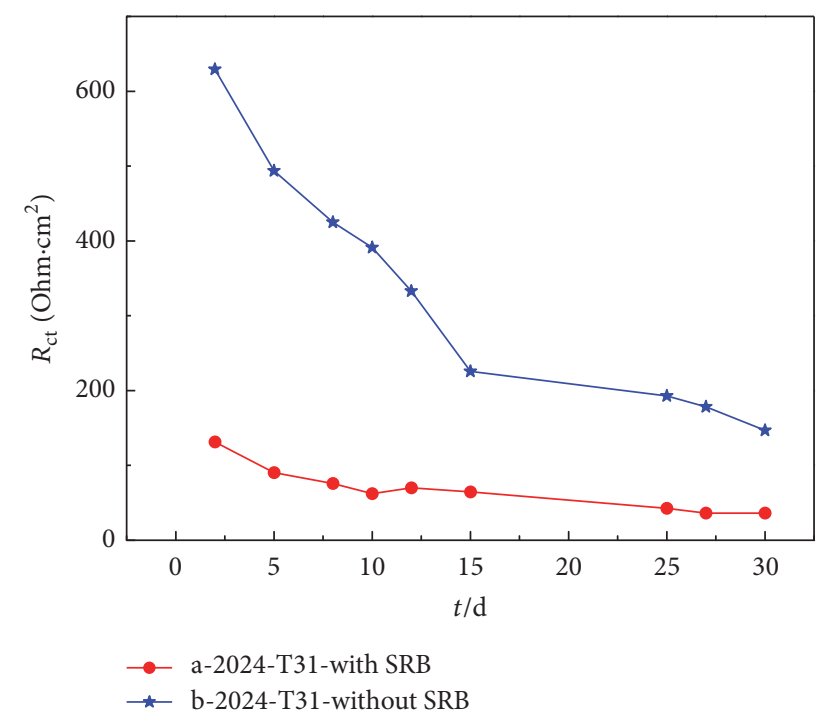

FIgURE 7: The evolution of $R_{\mathrm{ct}}$ of 2024-T31 aluminum-magnesium alloy in different medium systems.

nutrients in a test system are gradually consumed; SRB step into the decline period; a large amount of acid toxic metabolites such as $S$ and $S^{2}$ constantly aggregates on the surface, makes it very uneven, and forms localized corrosion cell of large cathode/small anode [21] which destroyed the protective effect of the passive film [22], which increased the corrosion current density and accelerated the corrosion of matrix.

The polarization of electrode indicates the rate of change of electrode potential with current density. If the polarization of electrode increases, the resistance of the electrode reaction will decrease and the reaction will proceed smoothly and vice versa [23]. Through the data of Table 2, we can figure out that the slope of the anodic polarization curve $\mathrm{A}$ is larger than that of the $B$ in system $A$, and the slope of the cathodic polarization curve $C$ is smaller than that in system $B$. This indicates that the existence of SRB hindered the anodic process of 2024T31 Al Mg alloy, promoted the cathodic depolarization, and accelerated the reaction of the cathode.

\subsection{Electrochemical Impedance Spectroscopy in Different Sys-} tems. Figures 5 and 6 are AC impedance spectra of two 2024-T31 aluminum-magnesium alloys which are soaking in experimental systems $\mathrm{A}$ and $\mathrm{B}$ for 2-30 d and fitting with Zsimpwin software, namely, the Nyquist plot and Bode diagram. Figure 7 is the equivalent circuit model fitted with Zsimpwin software, wherein $R_{s}$ is the resistance of experimental system, $R_{\mathrm{ct}}$ is the resistance of charge transfer, $Q_{d}$ is the double electric layers capacitor, $R_{f}$ and $Q_{f}$ are corrosion resistance and corrosion product capacitance which are formed by the role of biofilm and passivation film together, and $W$ is the Warburg impedance due to the passivation film.

It can be seen from Figure 5 that, in test system A, the Nyquist plot of 2024-T31 Al Mg alloy shows a phenomenon of alternating of one arc and two arcs whose radius is decreasing as time goes on. The phase angle of Bode plot firstly decreased to the high frequency mobile and then increased gradually to the low frequency mobile; the impedance value shows decrease as the decrease of frequency and then increase slightly and finally presents a decreasing trend with the reduced frequency. This is due to the interaction of biofilm and the passivation film; in the early immersion SRB multiply and form biofilm on the surface of the substrate; the corrosion damage of biofilm is greater than the formation of passivation film on the surface of matrix so that the impedance and the phase angle reduced, capacitive arc transition from a semicircle to two semicircles; the corrosion rate of the substrate increased [24]; in the midterm of immersion, the function of biofilm weakened; the corrosion of the substrate relative weakens and the impedance gradually increases while the microbes gradually died; in the later period of immersion, the acidic metabolites and toxic substances produced by the large amount of microorganisms deposited on the surface of the substrate, destroying the passive film on the substrate and increasing the corrosion rate. This analysis is consistent with the results of polarization curves.

Figure 6 shows that, in system B, with the increase of immersion time, there are two capacitive arcs on the Nyquist plot of 2024-T31 aluminum-magnesium alloy in the early immersion; they are all large capacitive arc of the high frequency and small capacitive arc of low frequency; arc radius is large. The capacitive arc of system significantly reduces and shows Warburg impedance starting from $5 \mathrm{~d}$; you can see two time constants in the Bode plot of the phase angle map; the phase angle moves towards low frequency and then increased gradually, with the impedance value gradually approaching a certain value with the increasing of immersion time and the decreasing of frequency. It is due to the passivation film on the surface of the substrate soaking in medium system B; it has a protective effect to the substrate and the radius of the arc is relatively large; Warburg impedance occurs after the first $5 \mathrm{~d}$; the shape is complex and the impedance value decreases for the original electrochemical control corrosion turns into the joint control of electrochemical and diffusion [22]. There are pits that occurred on passivation film as time goes on undermining the role of the passive film, corroding the substrate, and reducing the impedance.

Comparing Nyquist of Figure 4 with that in Figure 5, the impedance of the 2024-T31 aluminum-magnesium alloy is below $110 \Omega \cdot \mathrm{cm}^{-2}$ in system A and from $200 \Omega \cdot \mathrm{cm}^{-2}$ to $800 \Omega \cdot \mathrm{cm}^{-2}$ in system $\mathrm{B}$, higher than the impedance in bacteria containing medium. It indicated that SRB promoted the corrosion of 2024-T31 Al Mg alloy matrix.

Figure 6 is the fitted equivalent circuit model and Figure 7 shows the charge transfer resistance $R_{\mathrm{ct}} . R_{s}$ is the solution resistance of medium system, $Q_{d}$ is the electric double layer capacitor, $R_{f}$ and $Q_{f}$ are the corrosion products resistance and the corrosion products capacitance formed by the common action of the biofilm and the passive film, respectively. $W$ is the Warburg impedance due to the passive film. It can be seen from Figure 7, although $R_{\mathrm{ct}}$ of the system $\mathrm{A}$ and $\mathrm{B}$ will decrease with the extension of immersion time, the $R_{\mathrm{ct}}$ 

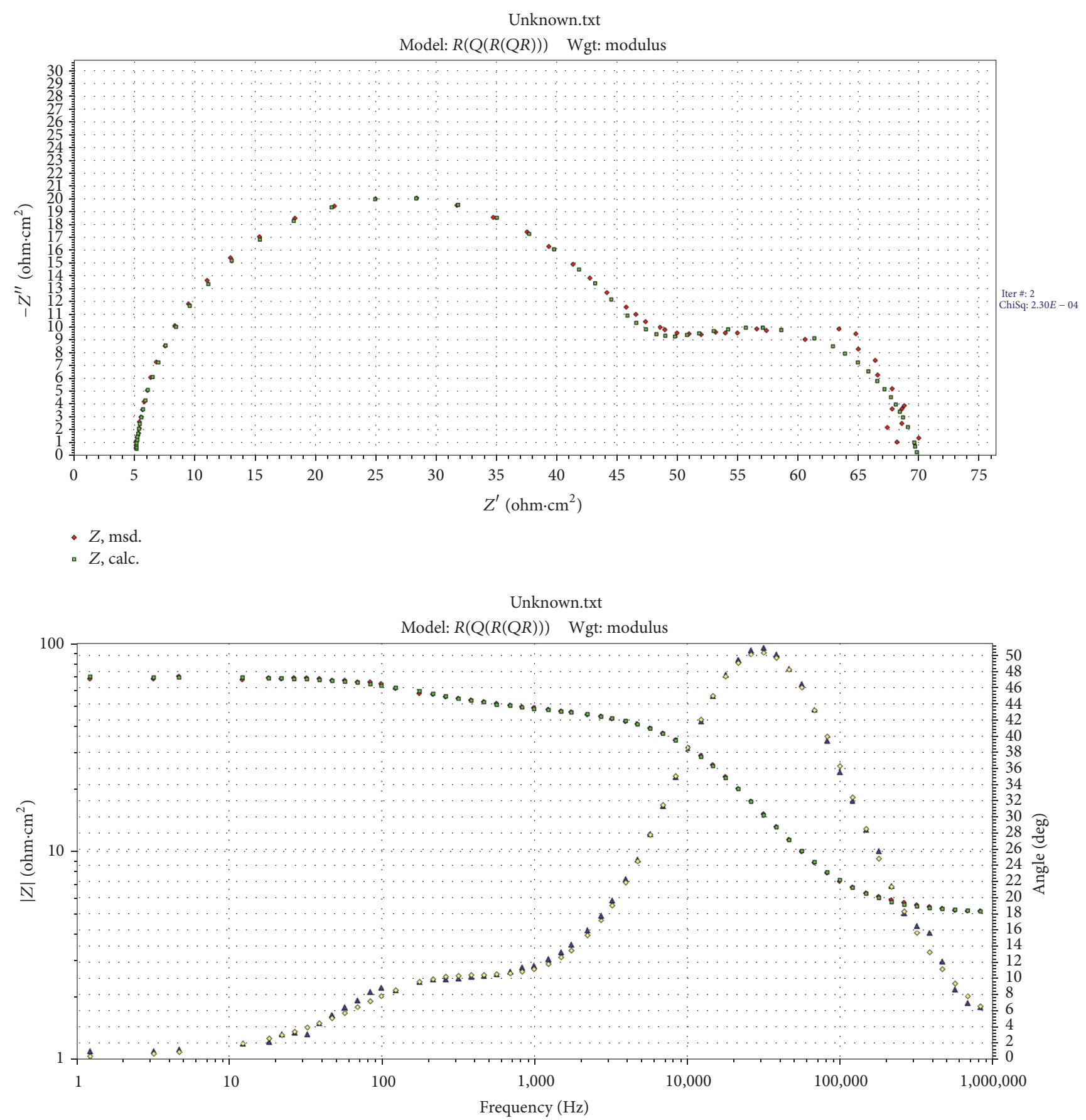

FIGURE 8: Comparison of the fitting results and the testing results.

of medium system A will always less than that of medium system $\mathrm{B}$ at the same time. The larger $R_{\mathrm{ct}}$ is, the smaller corrosion rate is [12]. The formation of the passivation film and the dissolution and breaking of the biofilm caused by the vital activities of SRB [25] accelerate the corrosion reaction process.

Figure 8 is the comparison of the fitting results and the testing results; it shows that the error is small, so the equivalent circuit we adopted is quite reasonable.

\section{Conclusions}

(1) Microbial SRB participate in and accelerate the corrosion of 2024-T31 aluminum-magnesium alloy matrix; pitting corrosion occurred after removing the corrosion products on the surface.

(2) The corrosion of 2024-T31 aluminum-magnesium alloy in bacterial oil-water system is jointly controlled by the passivation film and biofilm. In the initial stage of immersion, a loose uneven biofilm formed on the surface of substrate 
which isolated the material inside the membrane from outside, forming a local anaerobic zone on the surface of the substrate, promoting the growth of SRB, and accelerating the corrosion of the substrate; by midterm, the effect of biofilm gradually weakened while the protective effect of the passive film grew more insistently; the rate of corrosion slowed down; localized corrosion cell of large cathode/small anode formed on the surface of the substrate which accelerates the corrosion in the late immersion.

(3) The presence of microbial SRB restrains the anodic process of 2024-T31 aluminum-magnesium alloy and promotes the cathodic depolarization.

\section{Conflicts of Interest}

The authors declare that there are no conflicts of interest regarding the publication of this paper.

\section{References}

[1] Y. Huang, H.-C. Liu, L.-Q. Zhu, W.-P. Li, J.-Z. Liu, and X.-B. Ye, "Study on corrosion behavior of 30CrMnSiNi2A steels in simulated tank water environment," Journal of Materials Engineering, no. 4, pp. 88-92, 2012 (Chinese).

[2] Y. Cui, L. Ninh, and J. Li, "Corrosion of sulfate reducing bacteria in oil-water system," Corrosion and Protection, vol. 35, no. 4, pp. 393-396, 2014 (Chinese).

[3] Z. Feng, L. Chen, and H. Zhou, "Microbial corrosion of aircraft integral fuel tanks and related maintenance," Aviation Maintenance \& Engineering, no. 3, pp. 54-56, 2008 (Chinese).

[4] Q. Guan, H. Liu, L. Zhu et al., "Aluminum alloy cladding fouling in simulated tank water environment and its effect on the corrosion behavior," Materials Engineering, vol. 5, pp. 11-15, 2013 (Chinese).

[5] C. Li, L. Zhu, H. Liu, X. Ye, J. Liu, and Y. Huang, "Influence of temperature on initial corrosion behavior of Aluminum Alloy $2 \mathrm{~A} 12$ in simulated tank water environment," Acta Aeronautica et Astronautica Sinica, vol. 34, no. 6, pp. 1493-1500, 2013.

[6] G. Wang, "Analysis of common faults and treatment measures of aero engine," Technology Forum, vol. 63, 2016 (Chinese).

[7] C. McNamara, T. Perry, R. Leard, K. Bearce, J. Dante, and R. Mitchell, "Corrosion of aluminum alloy 2024 by microorganisms isolated from aircraft fuel tanks," Biofouling, vol. 21, no. 5-6, pp. 257-265, 2005.

[8] H.-Y. Chen, X. Li, X.-Y. Zhang, J.-B. Zeng, P.-M. Chen, and J. Yu, "Corrosion behavior of aluminum alloy under marine microbe SRB," Chinese Journal of Nonferrous Metals, vol. 25, no. 4, pp. 1080-1085, 2015 (Chinese).

[9] J. Li, Z. Xu, Y. Du et al., "Effect of sulfate reducing bacteria on corrosion electrochemical behavior of copper alloy," Chinese Journal of Corrosion and Protection, vol. 26, no. 7, pp. 342-347, 2007 (Chinese).

[10] W. Lee and W. G. Characklis, "Corrosion of mild steel under anaerobic biofilm," Corrosion, vol. 49, no. 3, pp. 186-199, 1993.

[11] H. Castaneda and X. D. Benetton, "SRB-biofilm influence in active corrosion sites formed at the steel-electrolyte interface when exposed to artificial seawater conditions," Corrosion Science, vol. 50, no. 4, pp. 1169-1183, 2008.
[12] F. M. AlAbbas, C. Williamson, S. M. Bhola et al., "Influence of sulfate reducing bacterial biofilm on corrosion behavior of lowalloy, high-strength steel (API-5L X80)," International Biodeterioration and Biodegradation, vol. 78, pp. 34-42, 2013.

[13] L. Qin, Study on Preparation, Corrosion and Friction Behavior of 2024 Aluminum Alloy Protective Films on the Surface, vol. 1, North Central University, Taiyuan, China, 2015 (Chinese).

[14] Q. Bao, D. Zhang, D. Lv, and P. Wang, "Effects of two main metabolites of sulphate-reducing bacteria on the corrosion of Q235 steels in 3.5wt.\% NaCl media," Corrosion Science, vol. 65, pp. 405-413, 2012.

[15] G.-P. Sheng, J. Xu, H.-W. Luo et al., "Thermodynamic analysis on the binding of heavy metals onto extracellular polymeric substances (EPS) of activated sludge," Water Research, vol. 47, no. 2, pp. 607-614, 2013.

[16] Y. Liu and P. Zhang, Principles of Metal Corrosion, Aviation Industry Press, Beijing, China, 1993 (Chinese).

[17] P. Angell, J.-S. Luo, and D. C. White, "Microbially sustained pitting corrosion of 304 stainless steel in anaerobic seawater," Corrosion Science, vol. 37, no. 7, pp. 1085-1096, 1995.

[18] S. Chen, P. Wang, and D. Zhang, "Corrosion behavior of copper under biofilm of sulfate-reducing bacteria," Corrosion Science, vol. 87, pp. 407-415, 2014.

[19] R. Javaherdashti, Microbiologically Influenced Corrosion: An Engineering Insight, Springer, London, UK, 2008.

[20] X. Li, W. Wang, J. Wang et al., "Effect of microbial film growth on the corrosion process of metals in seawater," Corrosion Science and Protection Technology, vol. 14, no. 4, pp. 218-222, 2002 (Chinese).

[21] W. Liu, X. Chang, Y. Zhang et al., "Stress corrosion mechanism and research method of aluminum alloy," Corrosion Science and Protection Technology, vol. 25, no. 1, pp. 1-73, 2013 (Chinese).

[22] X. Zhao, "Effects and control of sulfate reducing bacteria on corrosion behavior of marine steel," China Academy of Sciences, vol. 5, pp. 72-74, 2007 (Chinese).

[23] R. Zhu, J. Na, S. Guo et al., "Polarization behavior of J55 casing steel in presence of sulfate reducing bacteria," Corrosion and Protection, vol. 22, no. 4, pp. 147-172, 2001 (Chinese).

[24] S. Li, J. Sun, and J. Liu, "Study on microbial corrosion of aluminum alloy in fuel system," in Proceedings of the China Materials Conference, pp. 98-987, 2000 (Chinese).

[25] Y. Wan, D. Zhang, H. Liu, Y. Li, and B. Hou, "Influence of sulphate-reducing bacteria on environmental parameters and marine corrosion behavior of Q235 steel in aerobic conditions," Electrochimica Acta, vol. 55, no. 5, pp. 1528-1534, 2010. 

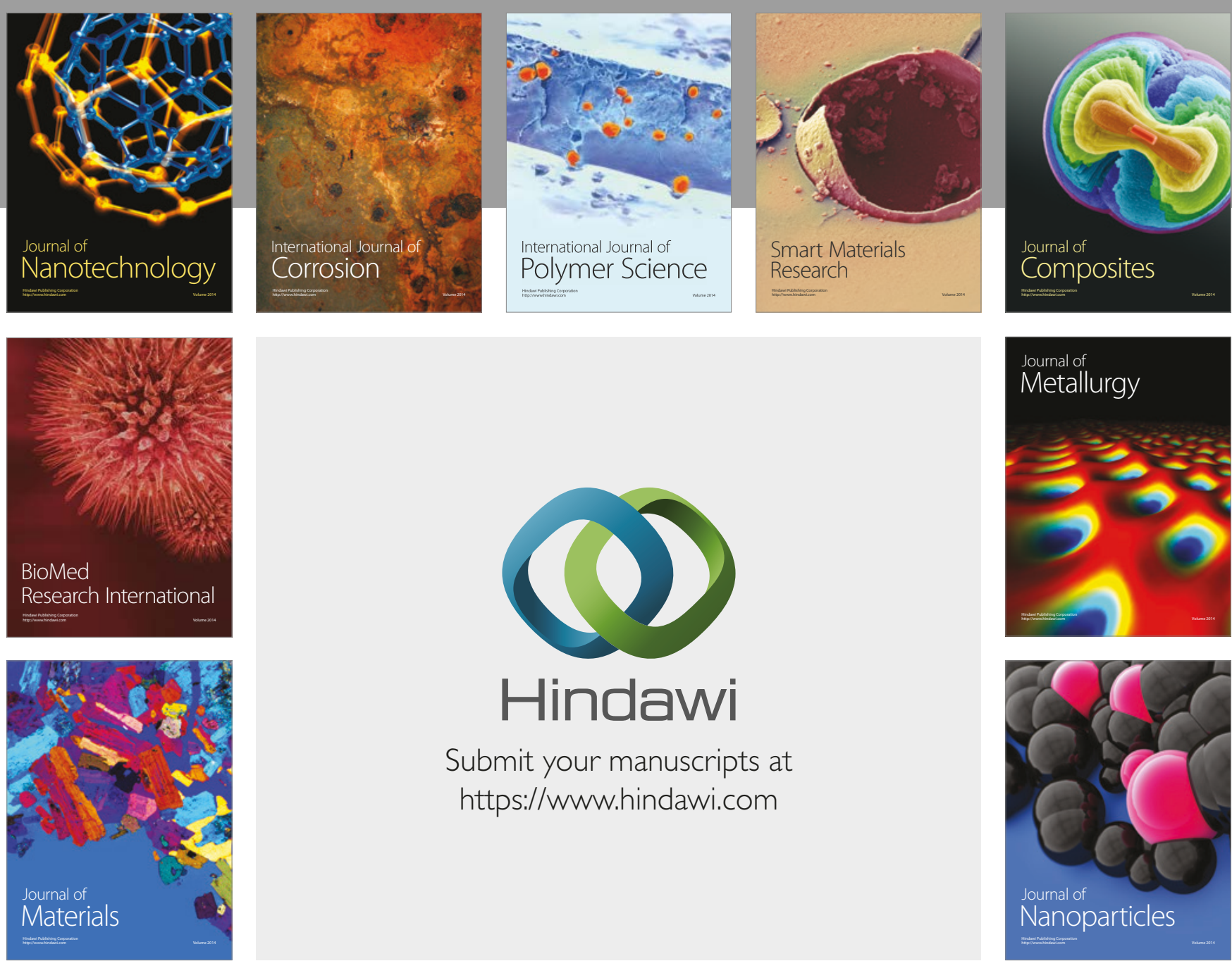

\section{Hindawi}

Submit your manuscripts at

https://www.hindawi.com
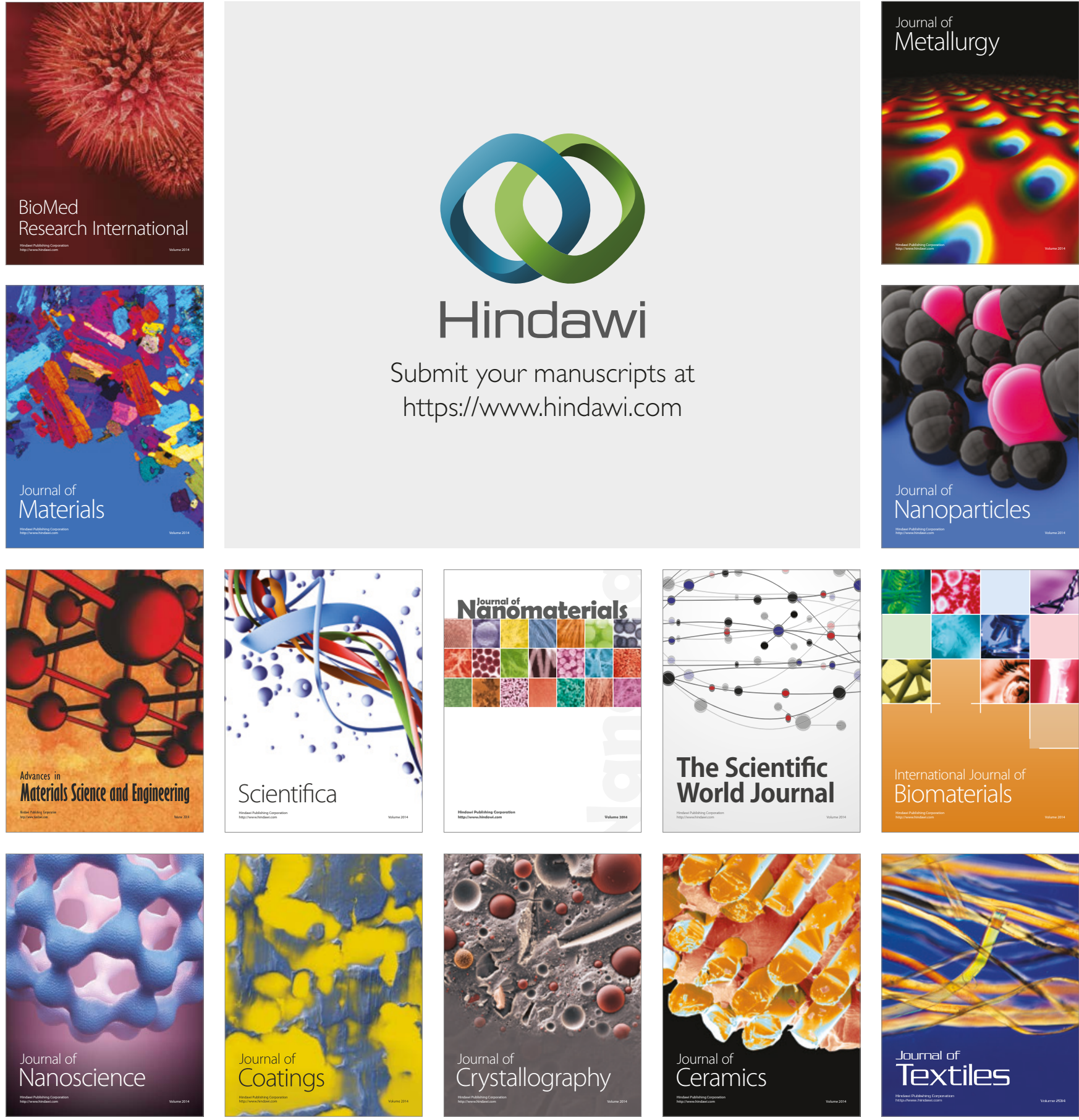

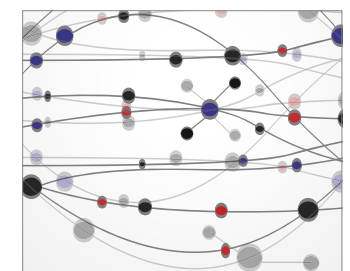

The Scientific World Journal
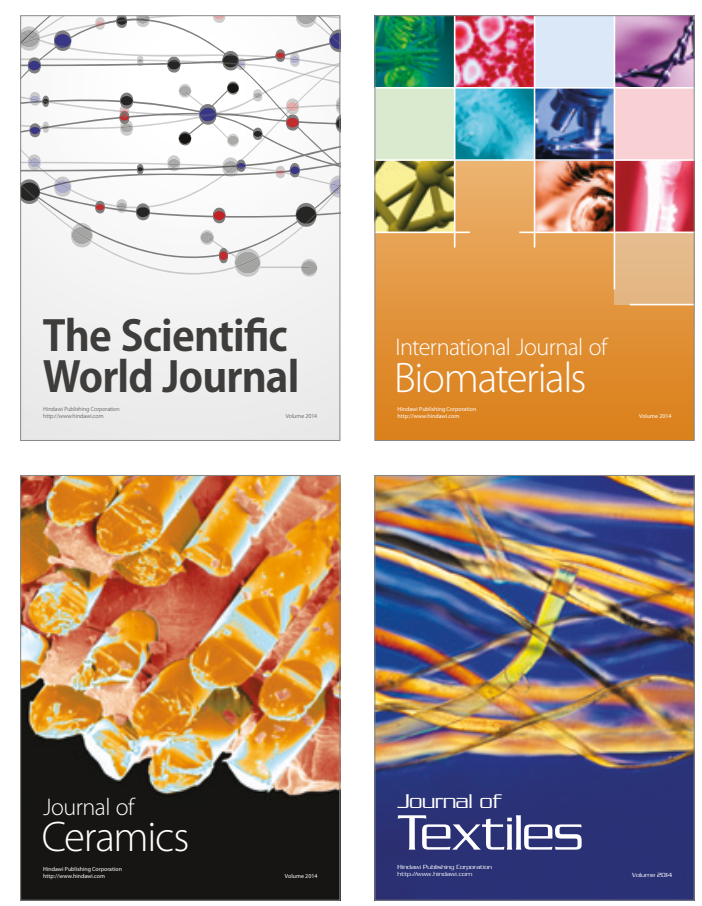